\title{
Metformin as a new anti-cancer drug in adrenocortical carcinoma
}

\author{
Giada Poli ${ }^{1, *}$, Giulia Cantini ${ }^{1, *}$, Roberta Armignacco ${ }^{1, *}$, Rossella Fucci ${ }^{1}$, Raffaella \\ Santi ${ }^{2}$, Letizia Canu ${ }^{1}$, Gabriella Nesi ${ }^{2}$, Massimo Mannelli ${ }^{1}$, Michaela Luconi ${ }^{1}$ \\ ${ }^{1}$ Endocrinology Unit, Department of Experimental and Clinical Biomedical Sciences "Mario Serio", University of Florence, \\ Florence Italy \\ ${ }^{2}$ Division of Pathological Anatomy, Department of Surgery and Translational Medicine, University of Florence, Florence Italy \\ *These authors contributed equally to this work \\ Correspondence to: Michaela Luconi, email: michaela.Iuconi@unifi.it
}

Keywords: metformin, H295R, IGF-1R, apoptosis, tumor proliferation

Received: March 24, 2016

Accepted: June 09, 2016

Published: July 06, 2016

\section{ABSTRACT}

Adrenocortical carcinoma (ACC) is a rare heterogeneous malignancy with poor prognosis. Since radical surgery is the only available treatment, more specific and effective drugs are urgently required. The anti-diabetic drug metformin has been associated with a decreased cancer prevalence and mortality in several solid tumors, prompting its possible use for ACC treatment.

This paper evaluates the in vitro and in vivo anti-cancer effects of metformin using the ACC cell model H295R.

Metformin treatment significantly reduces cell viability and proliferation in a doseand time-dependent manner and associates with a significant inhibition of ERK1/2 and mTOR phosphorylation/activation, as well as with stimulation of AMPK activity. Metformin also triggers the apoptotic pathway, shown by the decreased expression of Bcl-2 and HSP27, HSP60 and HSP70, and enhanced membrane exposure of annexin V, resulting in activation of caspase- 3 apoptotic effector. Metformin interferes with the proliferative autocrine loop of IGF2/IGF-1R, which supports adrenal cancer growth. Finally, in the ACC xenograft mouse model, obtained by subcutaneous injection of H295R cells, metformin intraperitoneal administration inhibits tumor growth, confirmed by the significant reduction of $\mathrm{Ki67 \%}$.

Our data suggest that metformin inhibits H295R cell growth both in vitro and in vivo. Further preclinical studies are necessary to validate the potential anti-cancer effect of metformin in patients affected by ACC.

\section{INTRODUCTION}

Despite its rarity (1:2 million prevalence), adrenocortical cancer (ACC) deserves more consideration on account of its aggressive behavior and poor prognosis when metastatic at diagnosis. To date, the best curative option is radical surgery. In case of advanced ACC, mitotane is the only available medical treatment $[1,2]$. Nevertheless, mitotane has proved to be of limited efficacy and poor tolerability, thus often reducing the patient's compliance. The drug's therapeutic range is reached in less than $50 \%$ of treated patients [1]; moreover, specific polymorphisms of the CYP2B6 gene have been associated with reduced circulating levels of mitotane, further decreasing its efficacy [3]. The mechanism by which mitotane acts on cancer cells, as well as on the normal adrenal, is still far from being fully elucidated. In such a scenario, it is mandatory to combine mitotane with other drugs, in order to improve the therapeutic efficacy and reduce treatment toxicity. Of the possible drugs that could be associated with mitotane, those safely and widely administered for treating other diseases, and eventually found to also exert anti-neoplastic effects, should offer the best therapeutic option. Metformin (1,1-dimethylbiguanide) is a biguanide cationic compound commonly used as an insulin-sensitizer and glucoselowering drug in the treatment of type 2 diabetes (T2D). Epidemiological studies and meta-analyses on large cohorts of diabetic patients have demonstrated a significant association between metformin and a reduced incidence 
of various types of solid tumors [4-7], supporting the potential use of metformin as an anti-cancer drug [8]. Several clinical trials are currently ongoing to specifically test metformin efficacy in cancer prevention and therapy [9, https://clinicaltrials.gov]. A considerable number of studies have demonstrated the anti-cancer activity of this drug both in in vitro and in vivo tumor models, highlighting a direct anti-proliferative and pro-apoptotic effect on cancer cells and an indirect action on metabolic regulation $[8,9]$.

The present paper investigates the in vitro and in vivo effects of metformin on the H295R adrenocortical cancer cell line.

\section{RESULTS}

\section{Metformin inhibits cell viability and proliferation in $\mathrm{H} 295 \mathrm{R}$ cells}

To investigate the effects of metformin on ACC, we first evaluated whether metformin interfered with viability in two available ACC cell lines, H295R and $\mathrm{SW} 13$. In vitro administration of increasing doses of metformin resulted in a dose- and time-dependent decrease of cell viability, which was statistically significant starting from 24 hours, as assessed by MTS assay in both the H295R (Figure 1A) and SW13 (Figure 1B) cell lines. Analysis of MTS dose-response curves allowed calculation of metformin inhibitory half doses $\left(\mathrm{IC}_{50}\right)$ for viability. Comparison of the $\mathrm{IC}_{50} \mathrm{~s}$ results revealed that the drug had a stronger effect on SW13 than H295R cells (Figure 1C, 1D).

Once shown that metformin significantly affected viability of both cell lines, we chose to focus on the effects in H295R, since this cell model better represents the secreting form of ACC. Inhibitory action of metformin was more pronounced when assessed by direct cell count (Figure 2A) than with MTS analysis; this suggests an additional effect on cell proliferation, as further confirmed by thymidine incorporation assay (Figure $2 \mathrm{~B}$ ). $\mathrm{IC}_{50} \mathrm{~s}$ were calculated from dose-response cell count (Figure 2C) and thymidine uptake (Figure 2D) curves for each time point: coherently, calculated $\mathrm{IC}_{50} \mathrm{~s}$ decreased with increased treatment time.

Since in non-tumor cells metformin acts as a hypoglycemic drug by facilitating glucose uptake and its utilization, we next evaluated these properties in the H295R cell line and found that metformin dosedependently stimulated a significant increase in cell basal glucose uptake (Table 1).

\section{Metformin inhibits ERK and mTOR signaling in H295R cells}

We next investigated the intracellular signaling pathways underlying metformin inhibitory effect on
H295R growth. We assessed the ability of the drug to activate the AMP-activated protein kinase (AMPK) energy sensor, via its phosphorylation in the Thr172 residue. Western blot analysis of cell lysates showed a significant dose-related AMPK phosphorylation stimulation, confirming that this intracellular pathway downstream from metformin action is also activated in H295R (Figure 3A, 3B).

Since in colon cancer metformin exerts an antiproliferative effect by suppressing IGF-1R signaling [10], we next analyzed the activating phosphorylation pattern for Akt and extracellular signal-regulated kinases 1/2 (ERK1/2), the two main IGF-1R downstream pathways in H295R cells [11]. Increasing doses of metformin inhibited phosphorylation of both ERK1 and 2 (Figure 3C, 3D), with no significant effect on Akt phosphorylation (data not shown). Signaling pathways downstream from IGF-1R have been shown to converge in MTOR activation to sustain cell proliferation in both H295R [12,13] and ACC [14]. A 24 hour metformin treatment induced a dose-dependent inhibition of mTOR activating phosphorylation in the Ser2448 residues (Figure 3E, 3F), as well as a significantly lower IGF-1R net expression (Figure 3G, 3H).

\section{Metformin activates the apoptotic process in H295R cells}

To investigate whether the reduced number of cells following metformin treatment could be due to an enhanced cell death, we next examined the cascade of events underlying apoptosis in H295R cells. Cytofluorimetric analysis of annexin $\mathrm{V}$ exposure (Figure 4A), shows that 48 hour treatment of the cells with increasing doses of metformin (10, 20, $50 \mathrm{mM}$ ) stimulates a dose-dependent increase in the percentage of apoptotic cells, both in early and late phases of the apoptotic process, compared with controls (Figure 4A, 4B). This finding is associated with a significant decrease in the number of living cells. Our findings were confirmed by a protein array specifically designed to assess the expression of the main proteins involved in the apoptotic pathway. H295R cells treated with $20 \mathrm{mM}$ metformin for 48 hours expressed lower levels of the anti-apoptotic proteins Bcl-2 and Bcl-w, uncleaved caspase 3 and heat shock proteins HSP27, HSP60 and HSP70 (Figure 4C). Decreased IGF2 expression was also observed, confirming the inhibitory effect of metformin on the autocrine/paracrine IGF2/IGF-1R system. Western blot analysis of the same protein extracts revealed that $20 \mathrm{mM}$ metformin inhibited $\mathrm{Bcl}-\mathrm{xl}$ form (Figure 4D) and activated caspase- 3 by increasing the cleaved fragments and decreasing the corresponding uncleaved form (Figure 4E). 


\section{Metformin affects tumor growth in vivo in a mouse ACC xenograft model}

In order to evaluate the in vivo metformin effect, we monitored tumor growth in a mouse xenograft ACC model, obtained by subcutaneously injecting H295R cells in the two groups of athymic CD-1 nude mouse strain $[15,16]$, one treated and one untreated with metformin ( $3 \mathrm{mg} /$ day) for 40 days. Metformin administration was associated with a statistically significant reduced increase in tumor volume after 27 days compared with controls, (Figure 5A). After 15 days of treatment, the inhibitory effect $(1-\mathrm{T} / \mathrm{C}=76.2$ $\pm 8.4 \%)$ approached the maximum $(89.8 \pm 6.7 \%)$, which was reached on day 27th and remained almost constant until the animals were sacrificed $(80.2 \pm 14.0 \%$ inhibition on day 40th).

Macroscopically, excided tumors from the control group were larger, generally lobulated and highly vascularized (Figure 5B) compared with those from the treated group, which were smaller and well-circumscribed (Figure 5C).

Histologically, the tumors from the controls consisted of rather small, uniform cells with coarse chromatin and prominent nucleoli. A haphazard network of small-caliber vessels was also observed (Figure 5D). Mitotic figures, both typical and atypical, were numerous (Figure 5D, asterisks). Conversely, in the metformin-treated group, the tumors showed decreased vascularization, a greater number of apoptotic bodies (arrowheads) and a lower mitotic activity (Figure 5E). Foci of necrosis were occasionally seen (Figure 5E).

Immunohistochemistry demonstrated that tumor cells from both the controls (Figure 5F) and metformintreated (Figure 5G) mice stained intensely and diffusely with SF-1, confirming that they were H295R-derived. Metformin treatment (Figure 5I) was associated with a

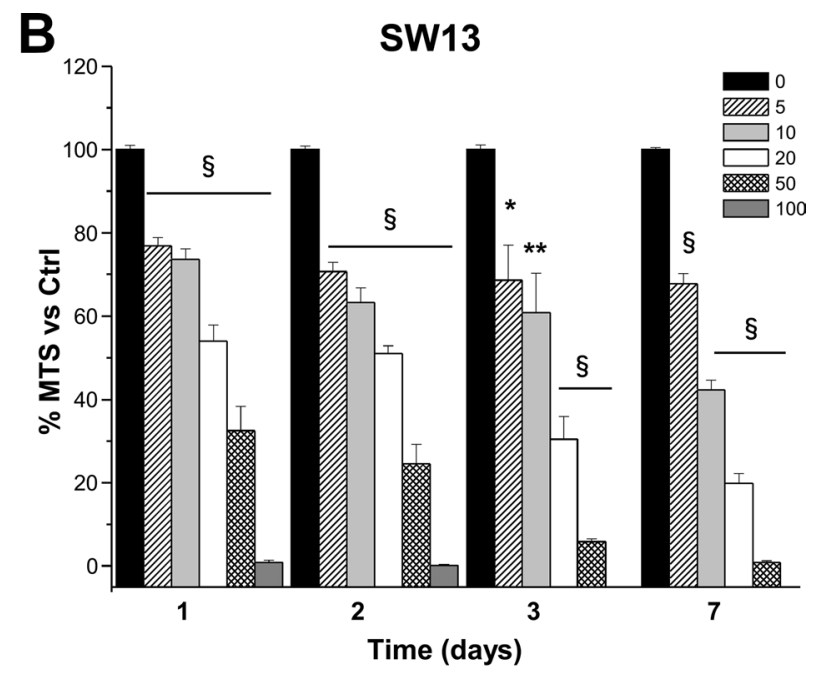

D
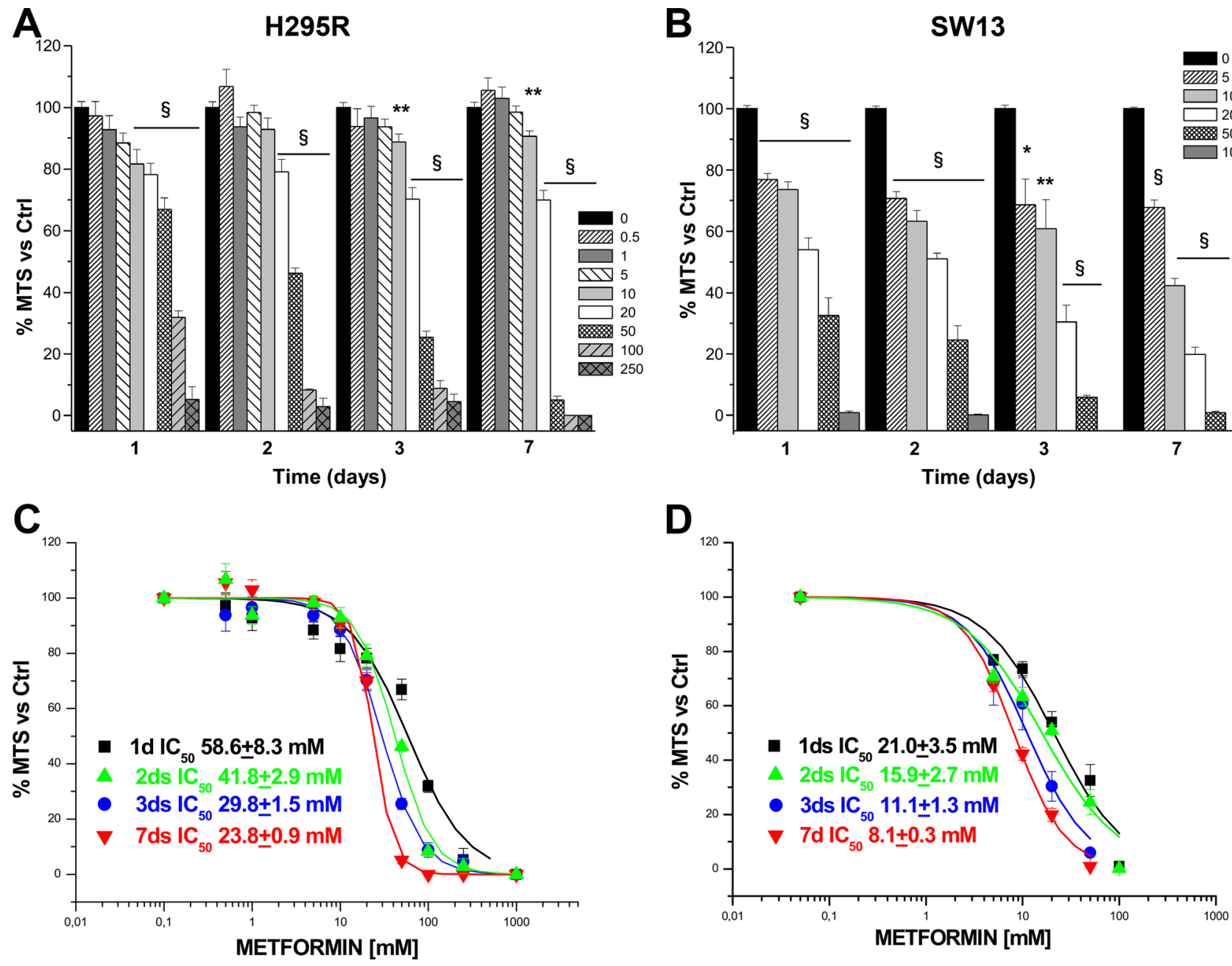

Figure 1: Metformin inhibits H295R and SW13 cell viability. Cell viability was assessed by using MTS assay in H295R (A) and SW13 (B) cells grown in the presence or absence of increasing doses of metformin ( $\mathrm{mM})$ at the indicated time points. Data are expressed as mean \pm SE of absorbance percentage vs. non-stimulated controls in $n=5$ independent experiments. Statistical analysis was performed with ANOVA followed by Dunnett's post hoc test: ${ }^{*} P<0.05,{ }^{*} P<0.01,{ }^{\S} P<0.0001$ vs respective controls. Metformin IC50s for cell viability were calculated on the dose-response curves obtained at the indicated time points in H295R (C) and SW13 (D) cell lines. 
reduction in nuclear Ki-67 reactivity, compared to the controls (Figure 5H) (Ki-67 mean \pm SEM: $55.1 \pm 1.8$ vs $74.8 \pm 5.2$ respectively; $P<0.02 ; 27 \%$ inhibition), suggesting an inhibitory effect of metformin on tumor proliferation.

Western blot analysis of protein extracts from excised tumors confirmed the findings observed in vitro in H295R (Figure 3A, 3B and 3E, 3F), that metforminin vivo treatment of the xenografted mice was associated with an increased level of p-AMPK (Figure 5J) and a decreased level of $\mathrm{p}$-mTOR (Figure 5K).

\section{DISCUSSION}

Meta-analyses conducted on diabetic subjects treated with metformin suggest a decreased incidence of several types of cancer $[6,7]$. Moreover, preclinical studies

A

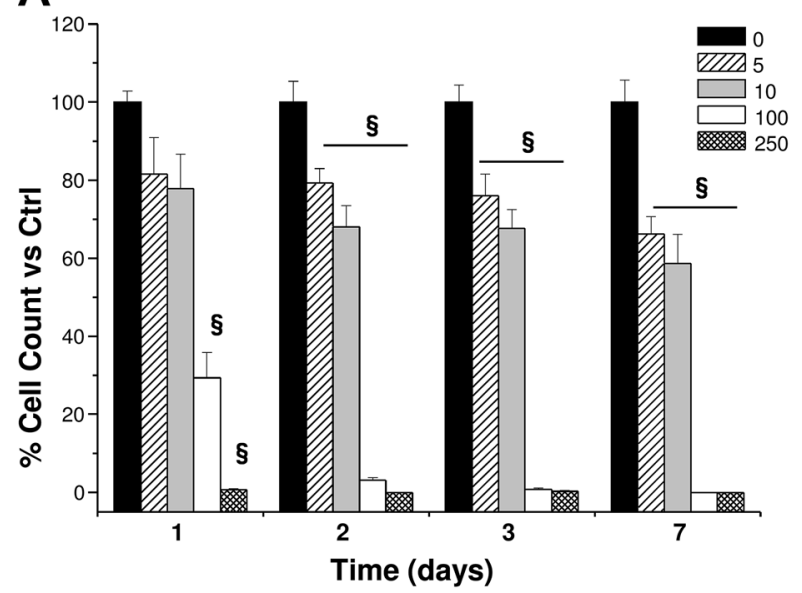

C

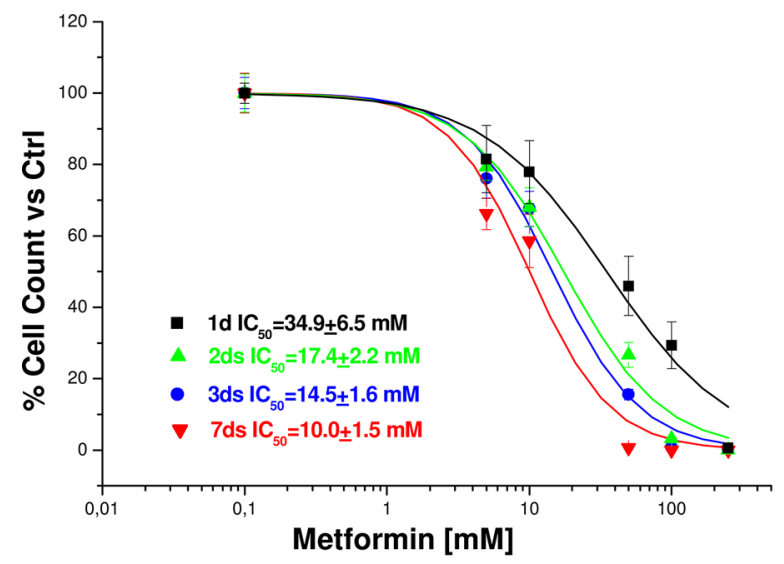

performed in vitro and in vivo on different types of solid tumors [8] have shown that metformin also possesses antitumor properties. In particular, this drug interferes with the insulin/IGF-1R system in tumor cells $[8,17]$ as shown in pancreatic $[10,18,19]$, breast $[20,21]$, endometrial $[22,23]$, prostate [24] and lung [25] cancers. Due to the rarity of ACC, no data are currently available regarding cancer prevalence and metformin treatment in $\mathrm{T} 2 \mathrm{D}$, nor on the effect metformin exerts on tumor growth. Our findings demonstrate that metformin inhibits proliferation in the adrenocortical cancer cell model H295R in association with a decreased expression of the IGF2/IGF-1R system. $\mathrm{ACC}$ is an endocrine tumor where the massive secretion of IGF2 acts in an auto/paracrine loop to sustain cancer cell proliferation, via activation of both insulin and IGF-1R pro-survival intracellular pathways [26-28]. In H295R, metformin induces a decrease in IGF2 and IGF-1R

\section{B}

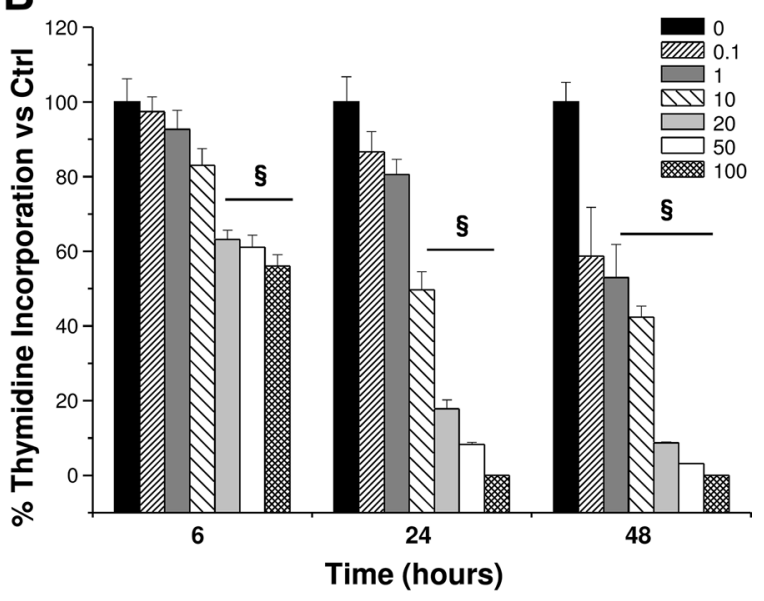

D

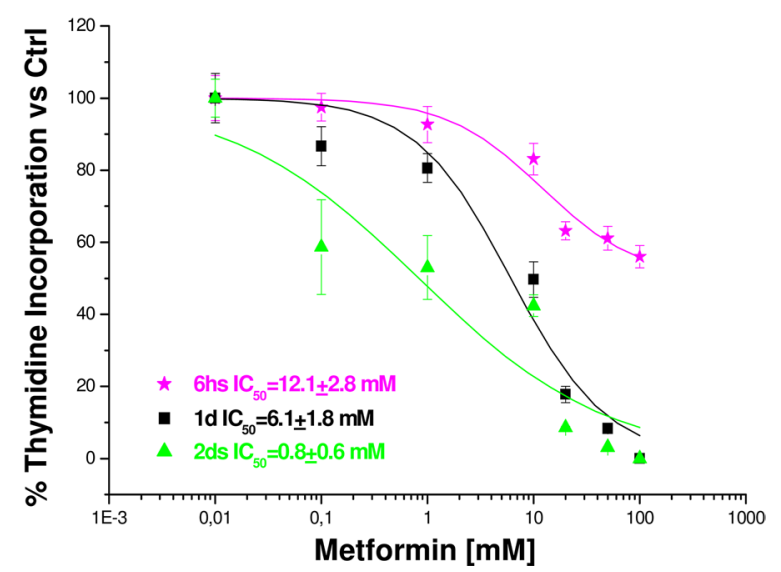

Figure 2: Metformin affects proliferation in H295R cell line. Cell proliferation was evaluated by direct cell count and thymidine incorporation (4 hour pulse) in H295R cells treated in absence or presence of increasing concentrations of metformin ( $\mathrm{mM}$ ) at the indicated time points. Data are expressed as mean $\pm \mathrm{SE}$ of cell count (A) or DNA-thymidine incorporation (B) percentage vs. non-stimulated controls in $n=3$ independent experiments. Metformin IC50s for cell count (C) and thymidine incorporation (D) were calculated on the doseresponse curves obtained at the indicated time points. Statistical analysis was performed with ANOVA followed by Dunnett's post hoc test: ${ }^{\S} P<0.001$ vs. respective controls. 
Table 1: Metformin stimulates glucose uptake in H295R

\begin{tabular}{|c|c|c|c|}
\hline Metformin (mM) & $\begin{array}{c}\text { Glucose uptake } \\
\text { (\% increase) }\end{array}$ & SE & $P$ value \\
\hline 0 & 100.0 & 5.98 & - \\
\hline 10 & 165.6 & 6.38 & 0.000 \\
\hline 20 & 161.8 & 5.21 & 0.000 \\
\hline 50 & 126.1 & 3.19 & 0.002 \\
\hline
\end{tabular}

The 2-deoxy- $\left[{ }^{3} \mathrm{H}\right]$ D-glucose uptake was measured in H295R cells treated for 24 hours with metformin and detected as radioactive counts per minute (CPM) on a scintillation beta counter. Data are expressed as mean $\pm \mathrm{SE}$ of percentage increase of glucose uptake vs. control without metformin $(0 \mathrm{mM}) . P$ values obtained by statistical analysis performed with ANOVA followed by Dunnett's post hoc test vs. control are indicated.

expression. The inhibition of IGF-1R promoter activity following metformin treatment could involve activation of p53, pAMPK and E2F1 transcription factor, which among the targets of metformin have been described to regulate IGF-1R gene expression [22, 23, 29].

In H295R cells, we showed that the drug also interferes with the intracellular ERK and mTOR signaling pathways downstream from IGF-1R. We previously demonstrated that another class of anti-diabetic drugs, the thiazolidinediones, including rosiglitazone and pioglitazone, inhibits adrenocortical cancer cell proliferation [11] and stimulates cell differentiation $[31,32]$. These drugs also restrained cell proliferation through IGF-1R signaling inhibition. However, while rosiglitazone acts on inhibition of both pathways, metformin seems to mainly affect ERK signaling, with no significant effect on phosphorylation/activation of Akt. A similar mechanism has been described in granulosa cells, where metformin inhibits IGF-1-stimulated cell growth through inhibition of ERK signaling and without affecting Akt [33]. Furthermore, the key role of ERK1/2 in mediating the anti-tumor effect of metformin has been confirmed by a xenograft mouse model using neuroblastoma cell lines, where a reduced ERK1/2 phosphorylation was observed in tumors of metformin-fed mice [34].

The inhibitory effect of metformin on cell growth seems due not only to a reduction in cell proliferation rate, but also to the stimulation of the mitochondrialdependent apoptotic pathway. Indeed, the complex I of the mitochondrial respiratory chain is one of the main cellular targets of metformin [8]. Metformin inhibition of the oxidative phosphorylation (OXPHOS) process reduces mitochondrial production of ATP, thus inducing cell energy stress and activating the intrinsic apoptotic pathway [8]. In H295R cells, we demonstrated that metformin treatment is associated with a dose-dependent increase of membrane exposure of annexin V, one of the early events in the apoptotic cascade. Protein array analysis also showed a significant decrease in the expression of the anti-apoptotic factors belonging to the family of $\mathrm{Bcl}-2$, the key regulator of the intrinsic apoptotic pathway and of mitochondrial integrity [35]. Induction of apoptosis finally results in the activation of the caspase-3 effector [35], the cleaved fragments of which become detectable in H295R cells following metformin treatment.

Inhibition of OXOPHOS leads to a reduction in the ATP/ADP ratio, thus activating the intracellular key energy sensor AMPK $[36,37]$. Activated AMPK mainly interferes with mTOR activity by disrupting its association with mTORC1 [38], finally resulting in a net cytostatic effect. In metformin-treated H295R cells, we observed an increased AMPK phosphorylation, associated with a rapid glucose uptake, which is probably an adaptive compensatory mechanism to fuel ATP production through glycolysis. However, in breast cancer, mTOR inhibition by metformin also blocks glycolytic and tricarboxylic acid cycle intermediates necessary for cancer proliferation [39], thus interfering with the Warburg effect [40]. Similarly, in H295R metformin-induced ERK inhibition and AMPK activation may converge in mTOR blockage. These findings suggest a metabolic switch from a mainly anabolic to a mainly catabolic state to also support energy requirements in the H295R cell line. The kinase protein mTOR acts as a gatekeeper for metabolism and cell growth, catching signals of cell stress, intracellular nutrient levels and growth factors [41]. Besides the PI3K/Akt activation pathway, which seems unaffected by metformin in H295R, mTOR can form an alternative complex with mTORC1 following ERK1/2 activation [42-44], thus specifically mediating the IGF-1/insulin proliferative pathway [12].

Metformin also induces a significant reduction in the expression of heat shock proteins (HSPs) involved in tumorigenesis [45]. The high rate of anabolic processes sustaining cancer cell proliferation and progression in a ROS-rich environment requires a high chaperone activity to ensure a correct protein folding process. Increased HSPs expression has been observed in various types of malignancies [46], including adrenocortical cancer [47]. In particular, HSP27, 60 and 70 play a pivotal role in dampening the apoptotic processes at mitochondrial level $[45,48]$, thus representing promising anti-tumor targets for the development of anti-cancer drugs. Here, we have demonstrated that metformin treatment leads to reduced HSP27/60/70 expression in H295R cells, which may contribute to the stimulatory effect of the drug on adrenal cancer cell apoptosis. 

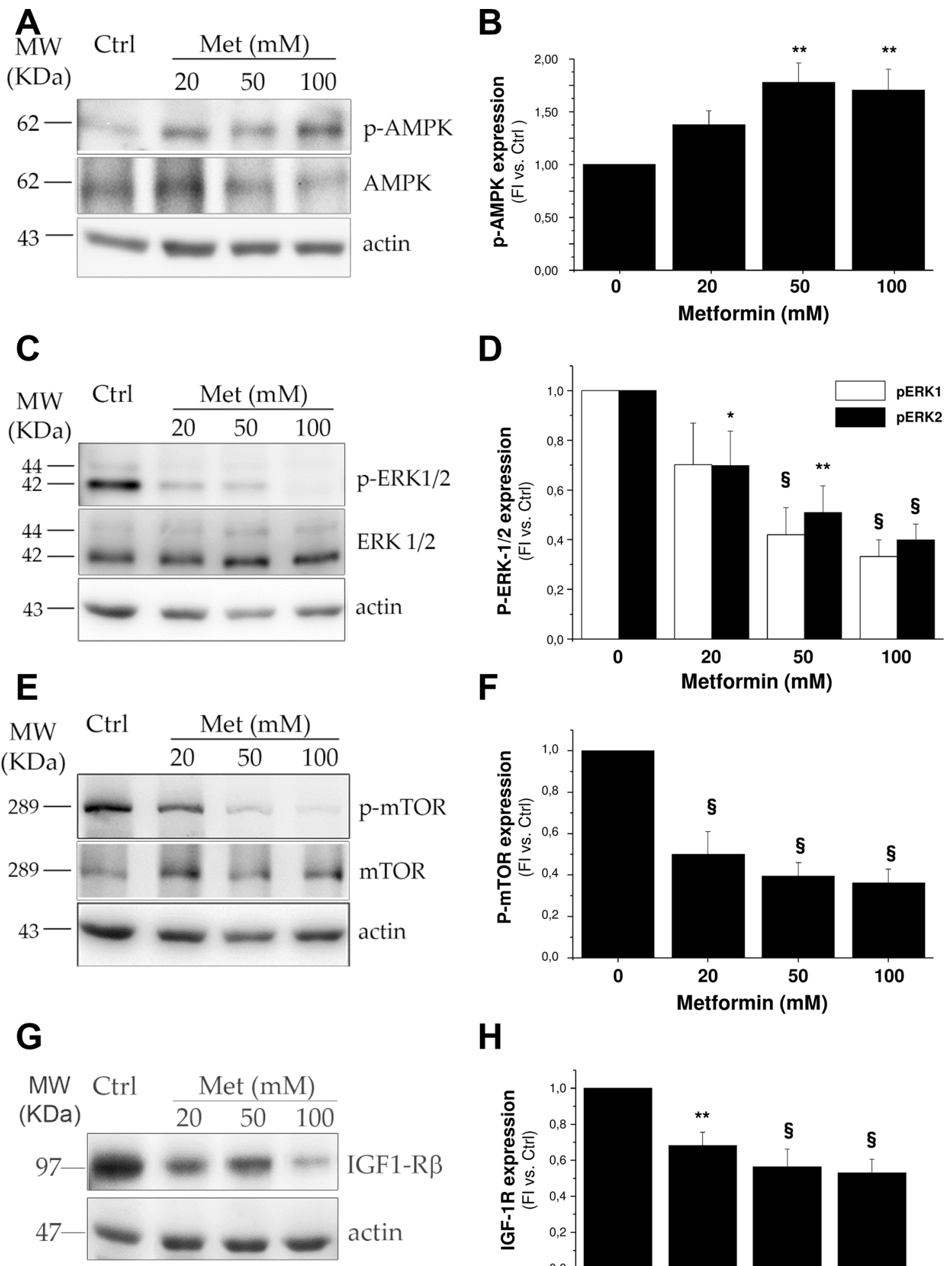

H

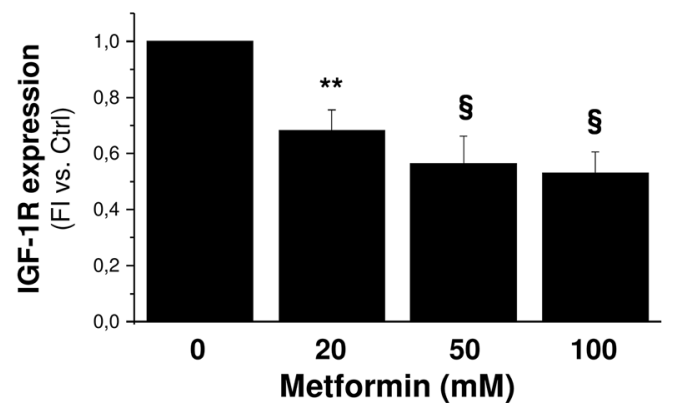

Figure 3: Metformin interferes with ERK and mTOR signaling pathways by activating AMPK. Protein extracts from H295R untreated or treated with increasing doses of metformin $(20,50,100 \mathrm{mM})$ were analyzed by Western Blot to assess AMPK (A) and mTOR (E) phosphorylation after 6 hour treatment, while phospho-ERK1/2 (C) and IGF-1R (G) expression was evaluated after 24 hour treatment. For AMPK, mTOR and ERK $1 / 2$ the total protein forms was also evaluated. Bar charts $(\mathbf{B}, \mathbf{D}, \mathbf{F}, \mathbf{H})$ represent mean $\pm \mathrm{SE}$ band intensity of each protein (p-AMPK, p-ERK1/2, p-mTOR, and IGF-1R, respectively) shown as the respective fluorescence intensity of Western blot bands normalized on actin, which was used as internal loading control, in at least three independent experiments. Statistical analysis was performed with ANOVA followed by Dunnett's post hoc test: ${ }^{*} P<0.05,{ }^{*} P<0.005,{ }^{\circledR} P<0.0001$ versus respective controls. 
A
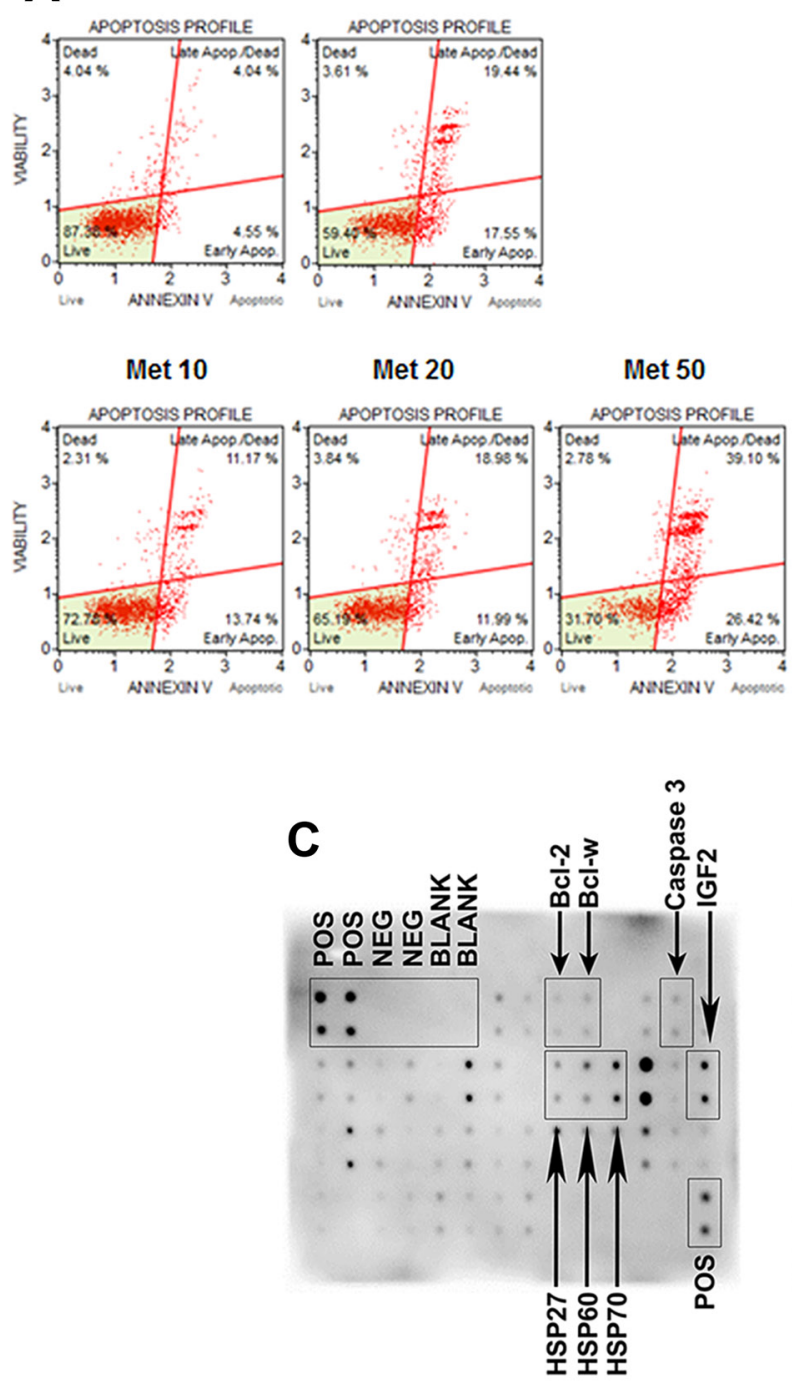

D

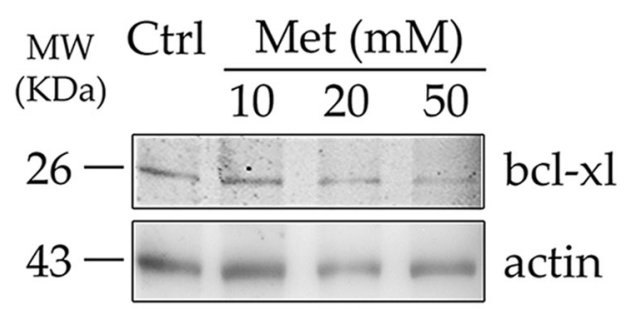

B
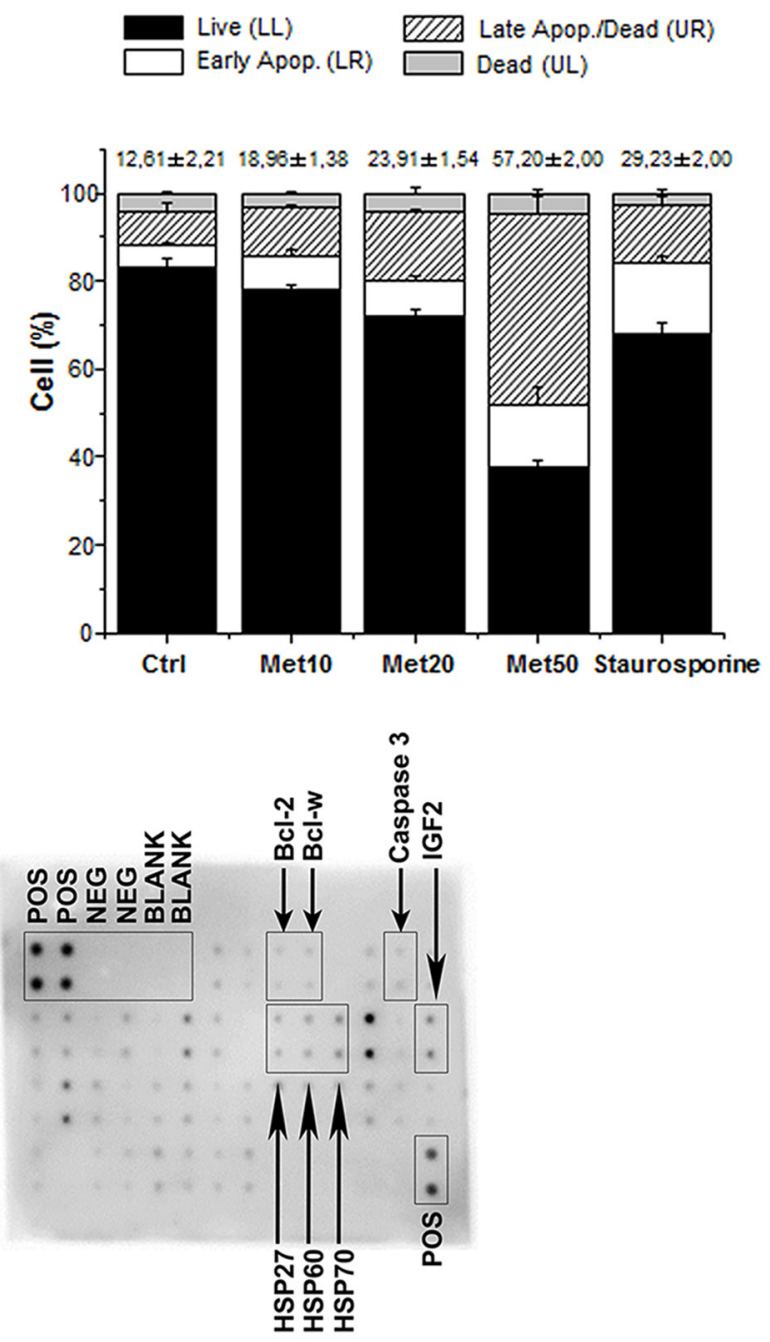

$\mathbf{E}$

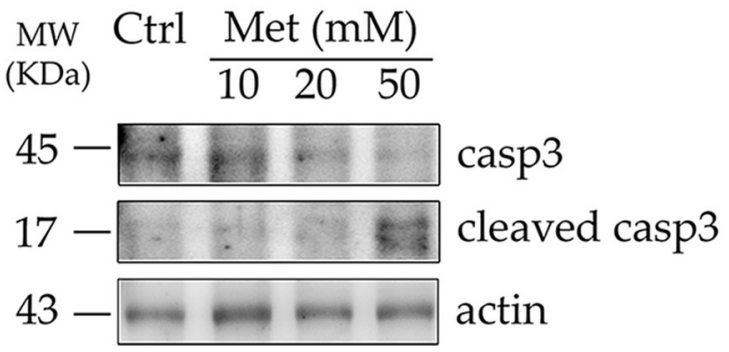

Figure 4: Metformin stimulates apoptosis in H295R cell line. (A) After 48 hour treatment with increasing doses of metformin (Met 10, 20, $50 \mathrm{mM}$ ), H295R cells were trypsinized and analyzed with a Muse automated cell analyzer, using the Muse Annexin V/Dead Cell Assay. This analysis enabled differentiation, on the basis of annexin V positivity, of four populations of cells for each sample: live, early apoptotic, late apoptotic, and dead cells. Cells treated overnight with $0.2 \mu \mathrm{M}$ staurosporine were used as positive controls of apoptosis induction. (B) Bar chart represents mean $\pm \mathrm{SE}$ of cell percentage for each population identified with Annexin $\mathrm{V}$ assay. Mean percentage $\pm \mathrm{SE}$ of total apoptotic cells related to each sample is also indicated above bar charts. Statistical analysis was performed with ANOVA followed by Dunnett's post hoc test: ${ }^{*} P<0.05,{ }^{*} P P<0.001,{ }^{\S} P<0.0001$ vs respective controls. (C) Protein array membranes for apoptosis were incubated with protein extracts from control (left panel) and $20 \mathrm{mM}$ metformin-treated for 48 hours (right panel) cells. Positive and negative spots are indicated, as well as the apoptosis proteins of interest (arrows). (D, E) Western blot analysis of protein extracts from H295R treated or untreated with the indicated doses of metformin for 48 hours: treated cells show decreased expression of Bcl-xl and an increase in the cleaved active fragments of caspase 3, accompanied by a decrease in the intact form, compared to the control. Actin was used as internal protein loading control. 

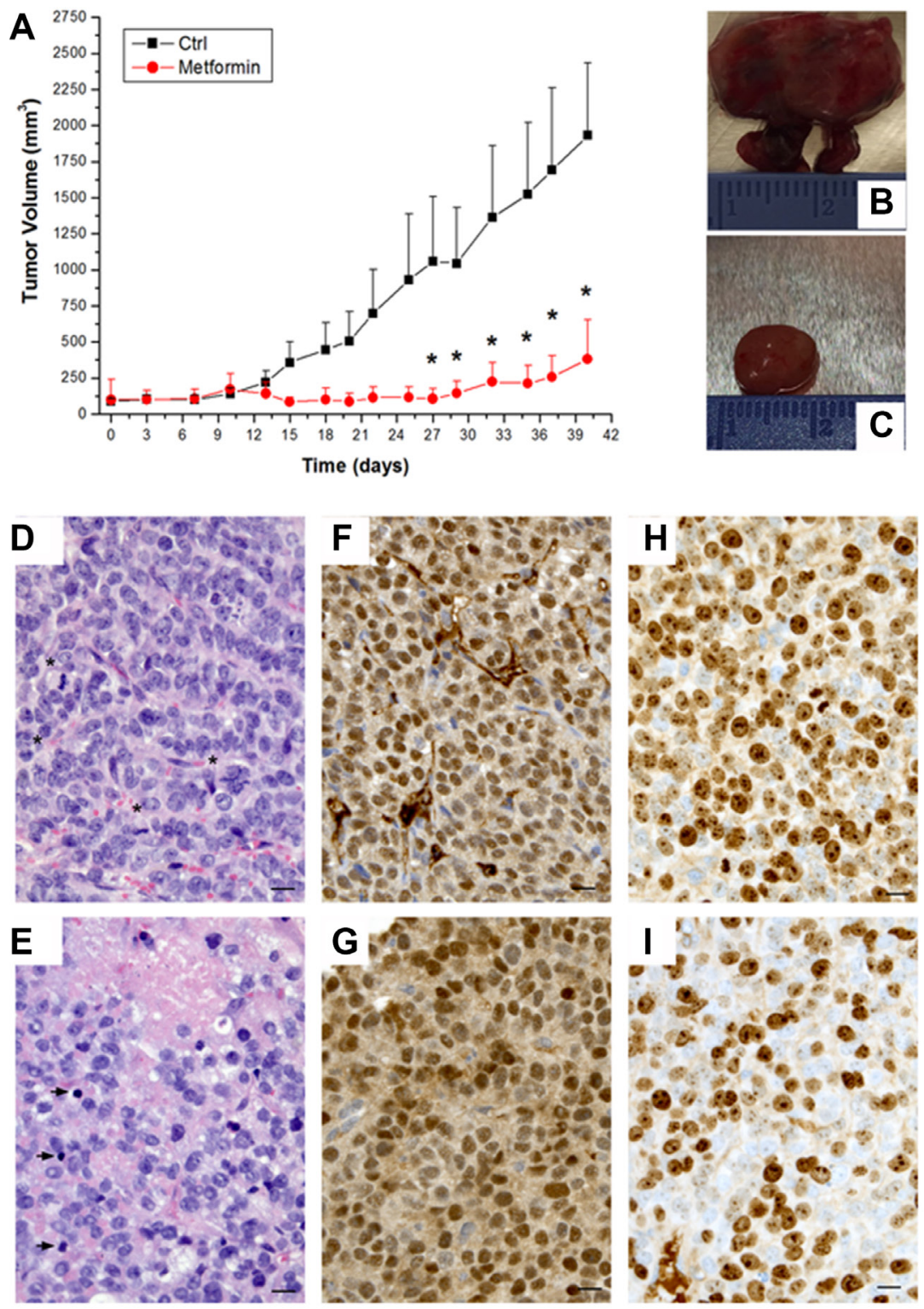

J

K
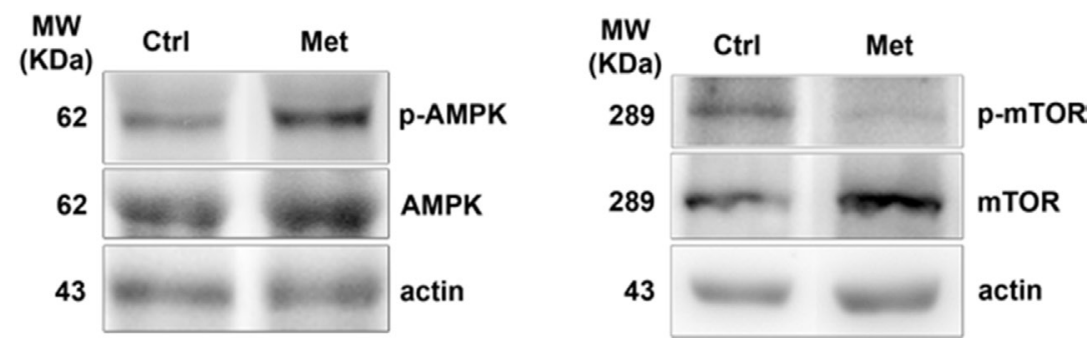

Figure 5: Metformin inhibits tumor growth in a mouse xenograft model of ACC. ACC xenografts were obtained by H295R cell subcutaneous injection in CD1 nude mice and, once tumors had reached a detectable $5 \mathrm{~mm}$ diameter, animals were randomized to be treated or not with metformin ( $3 \mathrm{mg} /$ day) for 40 days. Tumor growth was assessed by monitoring the mass volume 3 times a week. (A) Tumor growth curves represent mean $\pm \mathrm{SE}$ of the measured tumor volume over time in control mice (filled squares, $n=5$ ) and metformin-treated (filled circles, $n=5$ ) groups. ${ }^{*} P<0.05$ between the two groups was obtained by Student's $t$ test analysis. Analysis of two representative tumors excided after 40 day treatment (end of experiment) from both control and treated mice is given: $(\mathbf{B}, \mathbf{C})$ macroscopic observation; (D, E: 40× magnification) hematoxylin/eosin staining, asterisks and arrowheads indicate mitotic figures and apoptotic bodies, respectively; (F, G) immunohistochemistry for SF-1; (H, I) immunohistochemistry for Ki67; scale bare: $10 \mu \mathrm{m}$. Western blot analysis for p-AMPK (J, upper panel) and p-mTOR (K, upper panel) normalized on respective total protein forms (middle panels) and actin (lower panels) of two representative tumors excided from control and metformin-treated mice. 
The in vitro anti-proliferative effect of metformin in preclinical models is obtained by using higher doses than those reached in diabetic patients [49], thus apparently limiting its potential use in cancer treatment. However, in some tissues, metformin can accumulate at concentrations several-times higher than those found in the bloodstream [50], as demonstrated for the adrenal gland and liver [51]. The adrenal gland is in fact one of the tissues expressing the highest levels of the organic cation transporters 1 (Oct 1) and 3 (Oct 3) [52], which are responsible for metformin cellular uptake and for its high concentration in this organ [53]. Moreover, due to the high charge of the molecule, metformin specifically concentrates in mitochondria [36]. Thus, it is conceivable that the current metformin dosage used in T2D treatment, despite the micromolar levels reached in the plasma, could reach up to millimolar levels in actively absorbing organs, such as the adrenal cortex. We demonstrated a significant decrease in both tumor growth rate and H295R cell proliferation within the tumor mass in metformin-treated ACC xenografted mice, associated with an increase in AMPK and a decrease in mTOR phosphorylation similar to that observed for in vitro-treated H295R. These results were obtained in vivo employing a metformin dosage very similar to that used in diabetic patients and in line with the literature on rodent tumor xenograft models $[54,55]$, supporting the hypothesis of metformin concentration in the ACC tumor.

Several clinical trials, specifically designed with endpoints and outcomes allowing exploration of the anticancer properties of metformin, are currently ongoing [https://clinicaltrials.gov]. They will also serve to clarify the doses at which metformin exerts its anti-cancer effects compared with its anti-diabetic properties. Further studies are necessary to evaluate a possible combined therapy with mitotane, also proven to affect mitochondrial function in H295R [56, 57], to reduce the dosage of both drugs together.

In conclusion, our findings provide the first preclinical report on the anti-proliferative and proapoptotic effect of metformin in ACC and help to elucidate the intracellular signaling pathways involved. Mitochondrial functions and integrity are also the key targets for the anti-cancer activity of this drug in adrenocortical cancer cells. Further studies are necessary to validate these findings in vivo and better clarify the intracellular mechanisms involved in metformin activity, whilst proposing the prospective use of metformin in adrenocortical cancer therapy.

\section{MATERIALS AND METHODS}

\section{Reagents}

Primary antibodies directed against phosphoThr172-AMPK $\alpha 1 / 2$ (sc-33524), Actin (sc-1615), IGF-1R $\beta$ (sc-713) were from Santa Cruz Biotechnology, Inc. (Santa Cruz, CA, USA); anti-AMPK- $\alpha$, anti-phospho-p44/42 ERK1/2 (Thr202/Tyr204), anti-p44/42 ERK1/2, anti-
Bcl-xl and anti-mTOR antibodies were from Cell Signaling Technology, Inc. (Danvers, Mass, USA); antiphospho-Ser2448-mTOR (09-213), and anti-Caspase 3 (AB1899) antibodies were from Merck-Millipore (Darmstadt, Germany). Peroxidase-conjugated secondary antibodies, media and sera for cell cultures and metformin were from Sigma-Aldrich (Milan, Italy). Plastic ware was obtained from Corning (Milan, Italy). MTS solution (CellTiter96 ${ }^{\circledR}$ Aqueous One Solution Cell proliferation assay) was from Promega (Madison, WI, USA). [ $\left.{ }^{3} \mathrm{H}\right]-$ thymidine and 2-deoxy-[ $\left.{ }^{3} \mathrm{H}\right]$ D-glucose were provided by Perkin Elmer (Waltham, Massachusetts, USA). Other reagents for cell culture and microscopy were obtained from Sigma-Aldrich (Milan, Italy), except where specified.

\section{Cell cultures}

Human ACC cell lines H295R and SW13 were obtained from the American Type Culture Collection (Manassas, VA, USA) and used under passage 20. SW13 were cultured in DMEM/F-12 medium (SigmaAldrich) with 10\% FBS, $2 \mathrm{mM}$ L-glutamine, $100 \mathrm{U} / \mathrm{ml}$ penicillin-100 $\mu \mathrm{g} / \mathrm{ml}$ streptomycin, which was further enriched with a mixture of insulin/transferrin/selenium (Sigma-Aldrich) for H295R culturing. Cells were incubated at $37^{\circ} \mathrm{C}$ in a humidified $5 \% \mathrm{CO}_{2}$ atmosphere.

\section{MTS assay}

H295R and SW13 cells seeded in 96-well plates $\left(1 \times 10^{4}\right.$ and $2.5 \times 10^{3}$ cells/well, respectively $)$ were 24-hour starved and treated in 10\% FBS-medium with vehicle (control) or increasing metformin doses for the indicated time points. Media were replaced every three days. Cell viability was assessed by MTS assay, according to the manufacturer's instructions, and analyzed by an ELISA plate reader (Wallac 1420, PerkinElmer, Monza, Italy) at $490 \mathrm{~nm}$ wavelength to measure optical density (OD). Each experimental point was performed in six replicates in at least three independent experiments.

\section{Viable cell count}

H295R cells seeded in 12 -well plates $\left(1 \times 10^{5}\right.$ cells/ well) were $24 \mathrm{~h}$-starved and treated in $10 \%$ FBS-medium with vehicle (control) or increasing doses of metformin for the indicated time points. At each time point, cells were trypsinized and counted by a haemocytometer, after dead cell exclusion with trypan blue staining. The mean cell number was obtained by counting four replicates in three different experiments.

\section{DNA synthesis assay: $\left[{ }^{3} \mathrm{H}\right]$-thymidine (TdR) incorporation}

DNA synthesis was evaluated according to the amount of $\left[{ }^{3} \mathrm{H}\right] \mathrm{TdR}$ incorporated into trichloroacetic acid (TCA)-precipitated materials. Cells grown in 10\% FBS- 
complete medium till $70 \%$ confluence, were starved for 24 hours and treated with increasing doses of metformin for $6,24,48$ hours, pulsing them with $0.5 \mu \mathrm{Ci} / \mathrm{ml}\left[{ }^{3} \mathrm{H}\right]$ $\mathrm{TdR}(6.7 \mathrm{Ci} / \mathrm{mmol})$ for 4 hours before halting proliferation in ice-cold 10\% TCA. After washing in 5\% TCA, cells were solubilized in $0.25 \mathrm{~N} \mathrm{NaOH}$ and radioactivity was measured using a scintillation beta counter. Each experimental point was performed in four replicates in at least three independent experiments.

\section{Glucose uptake measurement}

H295R cells seeded in 12 -well plates $\left(1 \times 10^{5}\right.$ cells/ well) and grown up to confluence, were washed twice with PBS and $t$ incubated overnight in a serum free, low glucose medium $(0.55 \mathrm{mM})$. Cells were treated in the absence (control) or presence of increasing doses of metformin for 24 hours. After PBS-wash, cells were incubated with Hepes buffer (140 mM NaCl, $20 \mathrm{mM}$ Hepes-Na pH 7.4, $2.5 \mathrm{mM} \mathrm{MgSO} 4,1 \mathrm{mM} \mathrm{CaCl} 2,5 \mathrm{mM} \mathrm{KCl})$ containing 2-deoxy-[ $\left[{ }^{3} \mathrm{H}\right] \mathrm{D}$-glucose $[1 \mu \mathrm{Ci} / \mu \mathrm{l}]$ for 10 minutes at $37^{\circ} \mathrm{C}$. After wash with cold PBS, cells were lysed in $100 \mathrm{mM}$ $\mathrm{NaOH}$ for 1 hour at $37^{\circ} \mathrm{C}$. Radioactivity was measured by a scintillation beta counter.

\section{SDS-PAGE and western blot analysis}

Treated cells were lysed in RIPA buffer $(20 \mathrm{mM}$ Tris, $\mathrm{pH} 7.4,150 \mathrm{mM} \mathrm{NaCl}, 0.5 \%$ Triton-100, $1 \mathrm{mM}$ Na3VO4, 1 mM PMSF) and, after protein measurement by Comassie method, equal amounts of proteins for each sample $(30 \mu \mathrm{g})$ were separated by SDS-PAGE and transferred onto PVDF membranes (Immobilon, Merck Millipore). Each membrane was incubated overnight at $4^{\circ} \mathrm{C}$ with primary antibodies at the appropriate dilutions, then with peroxidase-secondary IgG (1:2000) at room temperature for 1 hour. Image acquisition and densitometric analysis were performed with Quantity One software on a ChemiDoc XRS instrument (BIORAD Labs, CA, USA). All Western blots were repeated in at least 3 independent experiments. Actin was used as internal loading control to normalize protein expression.

\section{Apoptotic evaluation by Muse TM $^{\mathrm{TM}}$ cytofluorimetric analysis}

After $72 \mathrm{~h}$ treatment with increasing doses of metformin $(0,10,20,50 \mathrm{mM}), \mathrm{H} 295 \mathrm{R}$ cells were trypsinized and analyzed with a Muse ${ }^{\mathrm{TM}}$ automated cell analyzer (Merck Millipore, Billerica, MA, USA) for apoptosis detection using the Muse ${ }^{\mathrm{TM}}$ Annexin V/Dead Cell (cat \# MCH100105, Merck Millipore, Billerica, MA, USA) assay, according to the manufacturer's instructions. Cells treated for 2 hours with $2 \mu \mathrm{M}$ staurosporine were used as positive control for apoptosis induction.

\section{Apoptosis antibody array}

Cell lysates from H295R cells treated or untreated with $20 \mathrm{mM}$ metformin for 48 hours were analyzed using a human apoptosis antibody array (RayBiotech, Norcross, GA, USA) according to the manufacturer's instructions. Array spot emission images were captured by ChemiDoc XRS instrument (BIO-RAD Labs, CA, USA).

\section{Xenograft model for tumor growth assessment}

Female athymic CD1 nude mice (9 week-old, Charles River Laboratories, Italy) were inoculated subcutaneously with H295R cell suspension $\left(7 \times 10^{6}\right.$ cells/100 $\mu \mathrm{l})$. Almost all H295R injected mice developed a detectable tumor except one (84\% overall tumor take rate), confirming the aggressiveness of ACC derived cells. Tumor growth was monitored daily and once solid tumors reached a $5 \mathrm{~mm}$ mean diameter the animals were randomly assigned to intraperitoneal injection of metformin (3 $\mathrm{mg}$ in $100 \mu \mathrm{l}$ PBS/day, 6 days/week) or vehicle. Tumor volume (mm3) was monitored 3 times a week by two independent investigators and was calculated by using the following formula: length $\mathrm{x}$ width ${ }^{2} / 2$. Anti-tumor activity of the drug was evaluated in terms of tumor growth inhibition percentage, calculated by 1 -Treated/Control tumor volume ratios (1-T/C) [58]. Data were expressed as mean $\pm \mathrm{SE}$.

Drug tolerability in tumor-bearing mice was assessed in terms of: a) lethal toxicity, i.e. any death in treated mice occurring before any death in control mice; b) body weight loss percentage $=100-$ (body weight on day $\mathrm{x} /$ body weight on day 1$) \times 100$, where $\mathrm{x}$ represents a day after or during the treatment period [58].

Animal studies were performed in compliance with an institutionally approved protocol and with the National Institutes of Health Guide for the Care and Use of Laboratory Animals.

\section{Histological and immunohistochemical examination of xenografts}

Tissues were fixed in 10\% buffered formalin and paraffin-embedded. Five-micrometer sections were hematoxylin and eosin $(\mathrm{H} / \mathrm{E})$ stained for histologic evaluation or used for immunohistochemistry. Immunohistochemical analysis with mouse anti-human Ki-67 monoclonal (Dako, Glostrup, Denmark) was performed with the Ventana Benchmark XT system (Ventana Medical Systems, Tucson, AZ, USA). Nuclei were hematoxylin counterstained. Ki-67 positive nuclei were counted on 1000 tumor cells in 3 tumors for each group. Negative controls were performed by omitting the primary antibodies. Immunohistochemical analysis with rabbit antihuman SF-1 polyclonal IgG (Upstate, Charlottesville, VA) was performed with the Ventana Benchmark XT system (Ventana Medical Systems, Tucson, AZ, USA). 


\section{Statistical analysis}

Statistical analysis was performed using SPSS 22.0 software (SPSS Inc. Chicago, IL, USA). The Kolmogorov-Smirnov test was used to verify the normal distribution of data which were then expressed as mean \pm SE. One way ANOVA followed by post-hoc Dunnett's test was applied for multiple comparisons, while Student's $t$ test was employed for comparing the two classes of data shown in figures. A $P<0.05$ value was considered statistically significant. The half Inhibitory Concentration $\left(\mathrm{IC}_{50}\right)$ of metformin was calculated on cell count, MTS and thymidine-incorporation dose-response curves using Origin software 6.1 version (OriginLab Corporation, Northampton, MA).

\section{ACKNOWLEDGMENTS}

We thank Prof. Paola Chiarugi, Dr. Giuseppe Castronovo, Dr. Tommaso Mello and Dr. Niccolò Bartalucci (University of Florence) for providing the antiphospho AMPK, anti-Caspase 3, anti-mTOR and anti-Bcl$\mathrm{xl}$ antibodies, respectively.

\section{CONFLICTS OF INTEREST}

The authors declare no conflicts of interest R. Armignacco, G. Cantini, L. Canu, M. Luconi, M. Mannelli, G. Nesi, G. Poli are members of the ENS@T (European Network for the Study of Adrenal Tumours).

\section{FUNDING}

The research leading to these results received funding from the Seventh Framework Programme (FP7/2007-2013) under grant agreement $\mathrm{n}^{\circ} 259735$ ENS@T-Cancer; from the FIRB fund of the Italian Minister of University, Research and Instruction (prot number: RBAP1153LS); from Associazione Italiana Ricerca sul Cancro AIRC (prot. IG2015-17691).

\section{REFERENCES}

1. Terzolo M, Angeli A, Fassnacht M, Daffara F, Tauchmanova L, Conton PA, Rossetto R, Buci L, Sperone P, Grossrubatscher E, Reimondo G, Bollito E, Papotti M, et al. Adjuvant mitotane treatment for adrenocortical carcinoma. N Engl J Med. 2007; 356:2372-80.

2. Fassnacht $M$, Terzolo $M$, Allolio B, Baudin E, Haak H, Berruti A, Welin S, Schade-Brittinger C, Lacroix A, Jarzab B, Sorbye H, Torpy DJ, Stepan V, et al. and FIRMACT Study Group. Combination chemotherapy in advanced adrenocortical carcinoma. N Engl J Med. 2012; 366:2189-97.

3. D'Avolio A, De Francia S, Basile V, Cusato J, De Martino F, Pirro E, Piccione F, Ardito A, Zaggia B, Volante M, Di
Perri G, Terzolo M. Influence of the CYP2B6 polymorphism on the pharmacokinetics of mitotane. Pharmacogenet Genomics. 2013; 23:293-300.

4. Evans JM, Donnelly LA, Emslie-Smith AM, Alessi DR, Morris AD. Metformin and reduced risk of cancer in diabetic patients. BMJ. 2005; 330:1304-5.

5. Decensi A, Puntoni M, Goodwin P, Cazzaniga M, Gennari A, Bonanni B, Gandini S. Metformin and cancer risk in diabetic patients: a systematic review and metaanalysis. Cancer Prev Res (Phila). 2010; 3:1451-61.

6. Johnson JA, Bowker SL. Intensive glycaemic control and cancer risk in type 2 diabetes: a meta-analysis of major trials. Diabetologia. 2011; 54:25-31.

7. Monami M, Colombi C, Balzi D, Dicembrini I, Giannini S, Melani C, Vitale V, Romano D, Barchielli A, Marchionni N, Rotella CM, Mannucci E. Metformin and cancer occurrence in insulin-treated type 2 diabetic patients. Diabetes Care. 2011; 34:129-31.

8. Pollak M. Potential applications for biguanides in oncology. J Clin Invest. 2013; 123:3693-700.

9. Quinn BJ, Kitagawa H, Memmott RM, Gills JJ, Dennis PA. Repositioning metformin for cancer prevention and treatment. Trends Endocrinol Metab. 2013; 24:469-80.

10. Karnevi E, Said K, Andersson R, Rosendahl AH. Metformin-mediated growth inhibition involves suppression of the IGF-I receptor signalling pathway in human pancreatic cancer cells. BMC Cancer. 2013; 13:235.

11. Cantini G, Lombardi A, Piscitelli E, Poli G, Ceni E, Marchiani S, Ercolino T, Galli A, Serio M, Mannelli M, Luconi M. Rosiglitazone inhibits adrenocortical cancer cell proliferation by interfering with the IGF-IR intracellular signaling. PPAR Res. 2008; 2008:904041.

12. Doghman M, El Wakil A, Cardinaud B, Thomas E, Wang J, Zhao W, Peralta-Del Valle MH, Figueiredo BC, Zambetti GP, Lalli E. Regulation of insulin-like growth factor-mammalian target of rapamycin signaling by microRNA in childhood adrenocortical tumours. Cancer Res. 2010; 70:4666-75.

13. Doghman M, Lalli E. Efficacy of the novel dual PI3-kinase/ mTOR inhibitor NVP-BEZ235 in a preclinical model of adrenocortical carcinoma. Mol Cell Endocrinol. 2012; 364:101-4.

14. De Martino MC, Feelders RA, de Herder WW, van Koetsveld PM, Dogan F, Janssen JA, Waaijers AM, Pivonello C, Lamberts SW, Colao A, de Krijger RR, Pivonello R, Hofland LJ. Characterization of the mTOR pathway in human normal adrenal and adrenocortical tumours. Endocr Relat Cancer. 2014; 21:601-13.

15. Luconi M, Mangoni M, Gelmini S, Poli G, Nesi G, Francalanci M, Pratesi N, Cantini G, Lombardi A, Pepi M, Ercolino T, Serio M, Orlando C, et al. Rosiglitazone impairs proliferation of human adrenocortical cancer: preclinical study in a xenograft mouse model. Endocr Relat Cancer. $2010 ; 17: 169-77$. 
16. Luconi M, Mannelli M. Xenograft models for preclinical drug testing: implications for adrenocortical cancer. Mol Cell Endocrinol. 2012; 351:71-7.

17. Pollak M. The insulin and insulin-like growth factor receptor family in neoplasia: an update. Nat Rev Cancer. 2012; 12:159-69.

18. Mohammed A, Janakiram NB, Brewer M, Ritchie RL, Marya A, Lightfoot S, Steele VE, Rao CV. Antidiabetic Drug Metformin Prevents Progression of Pancreatic Cancer by Targeting in Part Cancer Stem Cells and mTOR Signaling. Transl Oncol. 2013; 6:649-59.

19. Rozengurt E, Sinnett-Smith J, Kisfalvi K. Crosstalk between insulin/insulin-like growth factor-1 receptors and $\mathrm{G}$ protein-coupled receptor signaling systems: a novel target for the antidiabetic drug metformin in pancreatic cancer. Clin Cancer Res. 2010; 16:2505-11.

20. Zakikhani M, Dowling R, Fantus IG, Sonenberg N, Pollak M. Metformin is an AMP kinase-dependent growth inhibitor for breast cancer cells. Cancer Res. 2006; 66:10269-73.

21. Dowling RJ, Zakikhani $M$, Fantus IG, Pollak M, Sonenberg N. Metformin inhibits mammalian target of rapamycin-dependent translation initiation in breast cancer cells. Cancer Res. 2007; 67:10804-12.

22. Sarfstein R, Friedman Y, Attias-Geva Z, Fishman A, Bruchim I, Werner H. Metformin downregulates the insulin/ IGF-I signaling pathway and inhibits different uterine serous carcinoma (USC) cells proliferation and migration in p53-dependent or -independent manners. PLoS One. 2013; 8:e61537.

23. Xie Y, Wang JL, Ji M, Yuan ZF, Peng Z, Zhang Y, Wen JG, Shi HR. Regulation of insulin-like growth factor signaling by metformin in endometrial cancer cells. Oncol Lett. 2014; 8:1993-1999.

24. Kato H, Sekine Y, Furuya Y, Miyazawa Y, Koike H, Suzuki K. Metformin inhibits the proliferation of human prostate cancer PC-3 cells via the downregulation of insulin-like growth factor 1 receptor. Biochem Biophys Res Commun. 2015; 461:115-21.

25. Salani B, Maffioli S, Hamoudane M, Parodi A, Ravera S, Passalacqua M, Alama A, Nhiri M, Cordera R, Maggi D. Caveolin-1 is essential for metformin inhibitory effect on IGF1 action in non-small-cell lung cancer cells. FASEB J. 2012; 26:788-98.

26. Gicquel C, Raffin-Sanson ML, Gaston V, Bertagna X, Plouin PF, Schlumberger M, Louvel A, Luton JP, Le Bouc Y. Structural and functional abnormalities at $11 \mathrm{p} 15$ are associated with the malignant phenotype in sporadic adrenocortical tumours: study on a series of 82 tumours. J Clin Endocrinol Metab. 1997; 82:2559-65.

27. Logié A, Boulle N, Gaston V, Perin L, Boudou P, Le Bouc Y, Gicquel C. Autocrine role of IGF-II in proliferation of human adrenocortical carcinoma NCI H295R cell line. J Mol Endocrinol. 1999; 23:23-32.
28. Kirschner LS. The next generation of therapies for adrenocortical cancers. Trends Endocrinol Metab. 2012;23:343-50.

29. Schayek H, Bentov I, Rotem I, Pasmanik-Chor M, Ginsberg D, Plymate SR, Werner H. Transcription factor E2F1 is a potent transactivator of the insulin-like growth factor-I receptor (IGF-IR) gene. Growth Horm IGF Res. $2010 ; 20: 68-72$.

30. Alimova IN, Liu B, Fan Z, Edgerton SM, Dillon T, Lind SE, Thor AD. Metformin inhibits breast cancer cell growth, colony formation and induces cell cycle arrest in vitro. Cell Cycle. 2009; 8:909-15.

31. Ferruzzi P, Ceni E, Tarocchi M, Grappone C, Milani S, Galli A, Fiorelli G, Serio M, Mannelli M. Thiazolidinediones inhibit growth and invasiveness of the human adrenocortical cancer cell line H295R. J Clin Endocrinol Metab. 2005; 90:1332-9.

32. Betz MJ, Shapiro I, Fassnacht M, Hahner S, Reincke M, Beuschlein F; German and Austrian Adrenal Network. Peroxisome proliferator-activated receptor-gamma agonists suppress adrenocortical tumour cell proliferation and induce differentiation. J Clin Endocrinol Metab. 2005; 90:3886-96.

33. Tosca L, Ramé C, Chabrolle C, Tesseraud S, Dupont J. Metformin decreases IGF1-induced cell proliferation and protein synthesis through AMP-activated protein kinase in cultured bovine granulosa cells. Reproduction. 2010; 139:409-18.

34. Kumar A, Al-Sammarraie N, DiPette DJ, Singh US. Metformin impairs Rho GTPase signaling to induce apoptosis in neuroblastoma cells and inhibits growth of tumours in the xenograft mouse model of neuroblastoma. Oncotarget. 2014; 5:11709-22. doi: 10.18632/ oncotarget.2606.

35. Brenner D, Mak TW. Mitochondrial cell death effectors. Curr Opin Cell Biol. 2009; 21:871-7

36. Owen MR, Doran E, Halestrap AP. Evidence that metformin exerts its anti-diabetic effects through inhibition of complex 1 of the mitochondrial respiratory chain. Biochem J. 2000; 348 Pt 3:607-14.

37. Luengo A, Sullivan LB, Heiden MG. Understanding the complex-I-ty of metformin action: limiting mitochondrial respiration to improve cancer therapy. BMC Biol. 2014; 12:82.

38. Gwinn DM, Shackelford DB, Egan DF, Mihaylova MM, Mery A, Vasquez DS, Turk BE, Shaw RJ. AMPK phosphorylation of raptor mediates a metabolic checkpoint. Mol Cell. 2008; 30:214-26.

39. Janzer A, German NJ, Gonzalez-Herrera KN, Asara JM, Haigis MC, Struhl K. Metformin and phenformin deplete tricarboxylic acid cycle and glycolytic intermediates during cell transformation and NTPs in cancer stem cells. Proc Natl Acad Sci U S A. 2014; 111:10574-9.

40. Faubert B, Boily G, Izreig S, Griss T, Samborska B, Dong Z, Dupuy F, Chambers C, Fuerth BJ, Viollet B, 
Mamer OA, Avizonis D, De Berardinis RJ, et al. AMPK is a negative regulator of the Warburg effect and suppresses tumour growth in vivo. Cell Metab. 2013; 17:113-24.

41. De Martino MC, van Koetsveld PM, Pivonello R, Hofland LJ. Role of the mTOR pathway in normal and tumoural adrenal cells. Neuroendocrinology. 2010; 92 Supplymentary 1:28-34.

42. Winter JN, Fox TE, Kester M, Jefferson LS, Kimball SR. Phosphatidic acid mediates activation of mTORC1 through the ERK signaling pathway. Am J Physiol Cell Physiol. 2010; 299:C335-44.

43. Duong MT, Akli S, Wei C, Wingate HF, Liu W, Lu Y, Yi M, Mills GB, Hunt KK, Keyomarsi K. LMW-E/CDK2 deregulates acinar morphogenesis, induces tumourigenesis, and associates with the activated b-Raf-ERK1/2-mTOR pathway in breast cancer patients. PLoS Genet. 2012; 8:e1002538.

44. Muscella A, Vetrugno C, Calabriso N, Cossa LG, De Pascali SA, Fanizzi FP, Marsigliante S. [Pt(O,O'-acac) $(\gamma$-acac)(DMS)] alters SH-SY5Y cell migration and invasion by the inhibition of $\mathrm{Na}+\mathrm{H}+$ exchanger isoform 1 occurring through a PKC-E/ERK/mTOR Pathway. PLoS One. 2014; 9:e112186.

45. Calderwood SK, Gong J. Heat Shock Proteins Promote Cancer: It's a Protection Racket. Trends Biochem Sci. 2016; 41:311-23. doi: 10.1016/j.tibs.2016.01.003.

46. Wang C, Zhang Y, Guo K, Wang N, Jin H, Liu Y, Qin W. Heat shock proteins in hepatocellular carcinoma: Molecular mechanism and therapeutic potential. Int J Cancer. 2016; 138:1824-34.

47. Poli G, Ceni E, Armignacco R, Ercolino T, Canu L, Baroni G, Nesi G, Galli A, Mannelli M, Luconi M. 2D-DIGE proteomic analysis identifies new potential therapeutic targets for adrenocortical carcinoma. Oncotarget. 2015; 6:5695-706. doi: 10.18632/ oncotarget.3299.

48. Garrido C, Brunet M, Didelot C, Zermati Y, Schmitt E, Kroemer G. Heat shock proteins 27and70:anti-apoptotic protein swith tumourigenic properties. Cell Cycle. 2006; 5:2592-2601

49. Graham GG, Punt J, Arora M, Day RO, Doogue MP, Duong JK, Furlong TJ, Greenfield JR, Greenup LC, Kirkpatrick CM, Ray JE, Timmins P, Williams KM. Clinical pharmacokinetics of metformin. Clin Pharmacokinet. 2011; 50:81-98.
50. Wilcock C, Bailey CJ. Accumulation of metformin by tissues of the normal and diabetic mouse. Xenobiotica. 1994; 24:49-57.

51. Shingaki T, Hume WE, Takashima T, Katayama Y, Okauchi T, Hayashinaka E, Wada Y, Cui Y, Kusuhara H, Sugiyama Y, Watanabe Y. Quantitative Evaluation of mMate1 Function Based on Minimally Invasive Measurement of Tissue Concentration Using PET with [(11)C] Metformin in Mouse. Pharm Res. 2015; 32:2538-47.

52. Nies AT, Koepsell H, Winter S, Burk O, Klein K, Kerb R, Zanger UM, Keppler D, Schwab M, Schaeffeler E. Expression of organic cation transporters OCT1 (SLC22A1) and OCT3 (SLC22A3) is affected by genetic factors and cholestasis in human liver. Hepatology. 2009; 50:1227-40.

53. Beckmann R. [Absorption, distribution in the organism and elimination of metformin]. Diabetologia. 1969; 5:318-24.

54. Ben Sahra I, Laurent K, Loubat A, Giorgetti-Peraldi S, Colosetti P, Auberger P, Tanti JF, Le Marchand-Brustel Y, Bost F. The antidiabetic drug metformin exerts an antitumoral effect in vitro and in vivo through a decrease of cyclin D1 level. Oncogene. 2008; 27:3576-86.

55. Lonardo E, Cioffi M, Sancho P, Sanchez-Ripoll Y, Trabulo SM, Dorado J, Balic A, Hidalgo M, Heeschen C. Metformin targets the metabolic achilles heel of human pancreatic cancer stem cells. PLoS One. 2013; 8:e76518.

56. Poli G, Guasti D, Rapizzi E, Fucci R, Canu L, Bandini A, Cini N, Bani D, Mannelli M, Luconi M. Morphofunctional effects of mitotane on mitochondria in human adrenocortical cancer cells. Endocr Relat Cancer. 2013; 20:537-50.

57. Hescot S, Slama A, Lombès A, Paci A, Remy H, Leboulleux S, Chadarevian R, Trabado S, Amazit L, Young J, Baudin E, Lombès $M$. Mitotane alters mitochondrial respiratory chain activity by inducing cytochrome c oxidase defect in human adrenocortical cells. Endocr Relat Cancer. 2013; 20:371-81.

58. Hollingshead MG 2008 Antitumour efficacy testing in rodents. Journal of the National Cancer Institute 2008; 100:1500-1510. 